\title{
The abnormal expression of oxytocin receptors in the uterine junctional zone in women with endometriosis
}

\author{
Miaomaio Huang ${ }^{1,2+}$, Xuqing $\mathrm{Li}^{1 \dagger}$, Peipei Guo ${ }^{1}$, Zhaojuan $\mathrm{Yu}^{2}$, Yuting $\mathrm{Xu}^{1}$ and Zhaolian $\mathrm{Wei}^{1,2^{*}}$
}

\begin{abstract}
Background: The junctional zone (JZ), also called as the endometrial-myometrial junction, is related to peristaltic-like movements in the non-pregnant uterus. Hyperperistalsis and dysperistalsis of uterus constructions might underlie many important disorders such as dysmenorrhea, infertility, endometriosis, implantation failure. The major proteins for uterine contraction of the non-pregnant uterus may be Oxytocin (OT) and oxytocin receptor (OTR). The objective of this study was to inspect the expression of OTR in isthmic and mid-fundal parts of the uterine junctional zone at different stages of the follicular cycle in patients with and without endometriosis.
\end{abstract}

Methods: Uterine biopsies containing endometrium and junctional zone were collected from the isthmic and mid-fundal parts of the anterior wall after hysterectomy. The OTR expression was evaluated by immunohistochemistry.

Results: In the control uterus, OTR expression in the isthmic region was significantly higher than in the fundal region in the proliferative phase $(p<0.05)$ but significantly lower in the secretory phase $(p<0.05)$. And the expression of OTR in the proliferative phase was significantly higher than that in the secretory phase in both isthmic and fundal regions ( $p=0.000$ and 0.049 , respectively). However, in endometriosis uteri, OTR expression in the isthmic region showed no significant difference with that in the fundal region in both proliferative and secretory phases $(p=0.597$ and 0.736 , respectively). In both isthmic and fundal regions, OTR expression was not significantly different between the proliferative phase and secretory phase ( $p=0.084$ and 0.222 , respectively). OTR expression in fundal regions of revised ASRM I and II endometriosis were lower than that of revised ASRM III and IV $(p=0.049)$. In the fundal region of JZ, the expression of OTR in ovarian endometriosis was significantly lower than that in deep infiltrating endometriosis $(p=0.046)$. The expression level of OTR in the funds region is positively associated with the severity of dysmenorrhea in endometriosis group $(r=0.870, p<0.05)$. Comparing to normal uteri, the expression of OTR in the secretory phase was significantly higher in the endometriosis uteri $(p<0.05)$. In the fundus of endometriosis uteri, OTR expression was significantly higher in both the proliferative and secretory phases ( $p=0.045$ and 0.028 , respectively).

Conclusion: OTR expression in the JZ of women with endometriosis changes significantly, which may result in abnormal uterine contractile activity, reducing the endometriosis-related fertility and dysmenorrhea.

Keywords: Endometriosis, Oxytocin receptor, Junctional zone

\footnotetext{
*Correspondence: Weizhaolian_1@126.com

†Equal contributors

${ }^{1}$ Department of Gynecology and Obstetrics, First Affiliated Hospital of Anhui

Medical University, Meishan Road, Hefei 230000, China

${ }^{2}$ Assisted Reproductive Center, First Affiliated Hospital of Anhui Medical

University, Meishan Road, Hefei 230000, China
}

(c) The Author(s). 2017 Open Access This article is distributed under the terms of the Creative Commons Attribution 4.0 International License (http://creativecommons.org/licenses/by/4.0/), which permits unrestricted use, distribution, and reproduction in any medium, provided you give appropriate credit to the original author(s) and the source, provide a link to the Creative Commons license, and indicate if changes were made. The Creative Commons Public Domain Dedication waiver (http://creativecommons.org/publicdomain/zero/1.0/) applies to the data made available in this article, unless otherwise stated. 


\section{Background}

Endometriosis is a chronic disease characterized by the abnormal growth of the endometrial gland and stroma are present in locations other than the lining of the uterus [1, 2]. The JZ, also known as the inner myometrium, is the transitional interface between the endometrium and the outer myometrium [3]. It is not only functionally but also structurally different from the outer myometrium. In the non-gravid uterus, myometrial contractions exclusively distribute from this layer and their amplitude, frequency, and orientation are correlated with menstrual cycle phase [4-6]. These uterine contractions play vital roles in several reproductive processes, including of menstrual flow regulation, rapid sperm transport, successful implantation and deep placentation [5, 7-9]. The JZ seemingly gets involved in the process that determines endometriosis, infertility or pelvic pain. There was a study demonstrated the JZ contractions of isthmic in the proliferative phase were responsible for rapid sperm transport [9]. As for characterization of JZ, the three-dimensional transvaginal sonography can prove to be an accurate diagnostic tool that can be performed easily and repeatedly in patients with endometriosis in lower and advanced stages. The maximum thickness and alteration of JZ in women with endometriosis are significantly greater than those in women without endometriosis [10]. Endometriosis is often associated with $\mathrm{JZ}$ alteration even in the minimal and mild stages. JZ alteration could be considered as a beneficial and indirect sign to make a minimally invasive diagnosis of the disease. Thus, an accurate and analytical evaluation of JZ and its potential modification provides important information for women with endometriosis [11].

It is agreed that oxytocin, which can significantly increase the frequency of uterus peristaltic contractions, is one of the most vital mediators for regulating the contraction of uterus, not only in pregnancy but also during the non-pregnant states $[5,12,13]$. Oxytocin receptor is widely expressed in epithelial cells and smooth muscle cells of human uterus and peritoneal endometriotic lesions and ovarian endometriotic cysts [14]. Real time ultrasound has demonstrated peristaltic-like movements which are oxytocin-dependent are confined to the endometrium and JZ in non-pregnant uterus [5, 9]. According to the phases of menstrual cycle, many studies have shown the change of the amplitude, frequency and direction of the contractions of the junctional zone in normal uterus and uterus with endometriosis [5, 7, 8, 15]. Compared to the control, women with endometriosis showed an obvious uterine hyperperistalsis and dysperistalsis [15]. We previously showed the higher serum oxytocin level and higher frequency uterine contractions in endometriotic patients [16]. Abnormal uterine contractile activity might underlie important disorders such as dysmenorrhea, infertility, endometriosis, implantation failure, spontaneous miscarriage or preterm birth [17]. Strong evidence proves that uterus hyperperistalsis is significantly related to the progression of endometriosis [18]. To date, our knowledge is incomplete about the pathophysiologic mechanism governing eccentric contractile activity in the junctional zone in women of endometriosis. As far as we know OTR expression in the isthmus and fundus of $\mathrm{JZ}$ of at different menstrual phases in endometriosistic women has not been studied. Therefore, to understand the pathophysiological mechanisms governing abnormal uterine contractions surveyed in endometriosis, we inspected the OTR expression in isthmic and mid-fundal parts of the uterus at different stages of the follicular cycle in patients with and without endometriosis.

\section{Methods}

Subjects

The study was approved by the Ethics Committee of the First Affiliated Hospital of Medical University of Anhui (reference number: PJ20160409). There were two groups of patients with and without endometriosis. The mean age of patients in the endometriosis and control groups was $42.3 \pm 3.9$ and $41.5 \pm 4.1$ years old, respectively. The inclusion criteria for women with endometriosis were who had regular menstrual cycles (23-35 days), histologically confirmed endometriosis, experienced dysmenorrhea or not, received no hormone therapy or used an intrauterine device $\geq$ six months before hysterectomy. The exclusion criteria for study group were menopausal, adenomyosis, pelvic inflammatory disease and pregnancy 3 months before hysterectomy. Endometriosis and adenomyosis came to be seen as distinct entities. MRI is the method of choice for imaging and evaluation of JZ as an important diagnostic marker in the diagnosis of adenomyosis [19]. Because adenomyosis can be confidently diagnosed using MRI when the altered junctional zone thickness is greater than $12 \mathrm{~mm}$ and the expression pattern of oxytocin receptor in the junctional zone in women with adenomyosis had been studied by Zhang, women with evidence of adenomyosis were excluded from the scope of this study [20,21]. The strict inclusion and exclusion criteria can insure the validity of causal relationship of the findings with the endometriosis against the probably confounder factors exist in our study. The control group included women with regular menstrual cycles who underwent hysterectomy due to cervical intraepithelial neoplasia III (CIN III) or stage I cervical cancer, but with no history of primary dysmenorrhea, no evidence of endometriosis and adenomyosis through gynecological and sonographic examination before surgery, no hormone therapy or use of an intrauterine device $\geq$ six months before surgery. There were no evidences of endometriosis and adenomyoisis through surgical examination and histology after surgery. According 
with the principle of ethics, all samples containing endometrium and junctional zone must from the excised uterus. There was no evidence that OTR expression in smooth muscle cells of CIN III or stage I cervical cancer changed comparing with normal uterus. In many studies about OTR expression in smooth muscle cells, CIN III or stage I cervical cancer patients were listed as control groups $[13,20]$. Therefore, we incline to the view that OTR expression in JZ of CIN III or stage I cervical cancer patients have no changed compare with normal uterus. Based on the endometrial histology, there were 21 women with endometriosis, 15 women in the proliferative phase and 6 women in the secretory phase, as well as 48 women without endometriosis, with 26 women in the proliferative phase and 22 women in the secretory phase. In the control group, 9 patients suffered from secondary dysmenorrhea due to uterine leiomyoma. Dysmenorrhea is one of the most prevalent symptoms of uterine leiomyoma. High expression of myostatin and matrix- metalloproteinases-14 in uterine leiomyoma correlate with the presence of svere dysmenorrhea [22]. In many studies about OTR expression in smooth muscle cells, uterine leiomyoma patients were listed as control groups [13, 23]. Staging of endometriosis was performed according to the revised classification of the American Society of Reproductive Medicine (revised ASRM: $I=4 ; \quad I I=2 ; \quad I I I=8, \quad I V=7)$. Seventeen ovarian endometriosis (OEM) and four deep infiltrating endometriosis (DIE) patients were in the study group. The severity of the recent dysmenorrhea in the endometriosis group was evaluated by a $10-\mathrm{cm}$ Visual Analog Scale (VAS) before the surgery. The characteristics of the recruited patients of the case and control groups are listed in Table 1.

Table 1 Characteristics of the recruited patients with and without endometriosis

\begin{tabular}{llll}
\hline Variable & $\begin{array}{l}\text { Study group } \\
(n=21)\end{array}$ & $\begin{array}{l}\text { Control group } \\
(n=48)\end{array}$ & $P$ value \\
\hline Age (in year; mean \pm SD) & $42.3 \pm 3.9$ & $41.5 \pm 4.1$ & .419 \\
$\begin{array}{l}\text { Menstrual phase } \\
\quad \text { Proliferative }\end{array}$ & 15 & 26 & .179 \\
$\quad$ Secretory & 6 & 22 & NA \\
Indications for hysterectomy & & & \\
$\quad$ Cervical cancer & $2^{\text {a }}$ & 36 & \\
Ovarian endometriosis & 15 & 0 & \\
$\quad \begin{array}{l}\text { Deep infiltrating endometriosis } \\
\text { CIN III }\end{array}$ & 0 & 0 & \\
History of dysmenorrhea & & 12 & \\
No & $0(0 \%)$ & $39(81.3 \%)$ & .000 \\
Yes & $21(100 \%)$ & $9(18.7 \%)$ & \\
\hline
\end{tabular}

NA not applicable

a ovarian endometriosis

\section{Histological specimens}

The uterine junctional zone was defined as the inner third of the myometrium [24]. All samples containing endometrium and junctional zone were collected from the mid-fundal and isthmic areas of the uterine anterior wall. The uterus was opened along the sagittal plane after surgery. Multiple $1 \times 1 \times 1 \mathrm{~cm}^{3}$ samples were collected and fixed in buffered formaldehyde and processed routinely for paraffin embedding. Serial $4 \mu \mathrm{m}$ sections were prepared from each paraffin-embedded tissue block and handled for immunohistochemical staining. All uterine samples were examined by optical microscope to confirm presence of endometriosis, absence of adenomyosis and respective phases of the menstrual cycle. Under low light microscopy magnification, the uterine junctional zone was located just $3 \mathrm{~mm}$ below the endometrium [20].

After routine de-paraffinization and rehydration procedures, the slides were heated in a microwave oven (700 W) in citrate buffer saline (9.0) for twelve min and cooled at room temperature for antigen retrieval. Every sections were incubated with a drop of $3 \% \mathrm{H}_{2} \mathrm{O}_{2}$ deionized water (PV-6000, Wuxi, China) for $20 \mathrm{~min}$ at $37^{\circ} \mathrm{C}$ temperature. After 2 washes with phosphate-buffered saline (PBS), the slides were hatched with polyclonal rabbit anti-OTR (1:100 dilution, bs-1314R, Bioss, Beijing, China) overnight at $4{ }^{\circ} \mathrm{C}$ refrigerator. After 3 washes with phosphate-buffered saline (PBS), the sections were incubated with biotinylated anti-rabbit immunoglobulin G (1:400) for $30 \mathrm{~min}$ at room temperature. The bound antibody complexes were stained for 3 mins with diaminobenzidine. The slides were then washed, counterstained with hematoxylin, dried and mounted. Negative control sections were processed by omitting the primary antibody. Myometrium of pregnant uterus were used as positive controls. Immunoreactivity staining was characterized quantitatively by digital image analysis on the Image Pro-Plus 6.0 (Nikon, Japan). Images were obtained with a microscope fitted with a digital camera. A series of 4 random images on several sections were taken for each immunostained parameter to obtain a mean value. Staining was defined by color intensity, and a color mask was made. The mask was then applied equally to all images, and measurements were obtained. Immunohistochemical parameters were assessed in the area detected by total optical density and mean optical density, which is equivalent to the intensity of staining in the positive cells.

\section{Statistical analysis}

The results were presented as mean \pm standard error of the mean. Statistical Program for Social Sciences (SPSS) for windows version 16.0 (IBM Corp, Armonk, NY, USA) was used to perform statistical analysis. Statistical 
comparison of data was carried out by Student's $t$-test for non-paired samples. The normality tests showed that all data were in normal distribution. To evaluate possible effect of OTR expression levels on VAS score, a linear regression model was used. $P$-value less than $<0.05$ $(p<0.05)$ were considered statistically significant.

\section{Results}

The staining of OTR expression in the control uterus is showed in Fig. 1 and the quantitation of OTR expression in Fig. 2. OTR expression in the isthmic region of JZ was significantly higher than in the fundal region in the proliferative phase $(p=0.048)$ but significantly lower in the secretory phase $(p=0.012)$. In both isthmic and fundal regions of JZ, OTR expression in the proliferative phase was significantly higher than that in the secretory phase ( $p=0.000$ and 0.049 , respectively). OTR expression in patients with dysmenorrhea of control group was no significant difference from that of patients without in both isthmic and fundal regions of JZ ( $p=0.154$ and 0.175 , respectively).

The staining and quantitation of OTR expression of JZ in the endometriosis uteri are showed in Figs. 3 and 4, respectively. OTR expression in the isthmic region was slightly, but not significantly, lower than in the fundal region in both proliferative and secretory phases ( $p=0.597$ and 0.736 , respectivley). In both isthmic and fundal regions, the expression of OTR was not significantly different between the proliferative phase and secretory phase $(p=0.084$ and 0.222 , respectively). In the fundal region of JZ, the OTR expression was no significant difference between rASRM I and rASRM II stages of endometriosis $(p=0.919)$. Similarly, there was no significantly different of OTR expression in fundal part of JZ between rASRM III and IV stages of endometriosis $(p=0.445)$. However, OTR expression in fundal regions of revised ASRM I and II endometriosis were lower than that of revised ASRM III and IV $(p=0.049)$. The OTR expression in the isthmic region of $\mathrm{JZ}$ in ovarian endometriosis was no significantly different from that of deep infiltrating endometriosis $(p=0.357)$. In the fundal region of $\mathrm{JZ}$, the expression of OTR in ovarian endometriosis was significantly lower than that in deep infiltrating endometriosis $(p=0.046)$.

In the isthmic region, the expression of OTR in the endometriosis uteri showed no significant difference with that in control uterus in the proliferative phase $(p=0.139)$. However, the expression of OTR in the secretory phase was significantly higher in the endometriosis uteri $(p=0.007)$. In the fundal region of endometriosis uteri, the expression of OTR was significantly higher than that in the control uteri in not only the proliferative but also the secretory phases $(p=0.045$ and 0.028, respectively) Fig. 5.

We have also found that OTR expression level in the funds region is positively correlated with the severity of dysmenorrhea in women with endometriosis $(r=0.870$, $p<0.05$, Fig. 6).

\section{Discussion}

The temporal and spatial OTR distribution in the normal uterus would both change during the menstrual cycle, which are consistent with Zhang et al. [20]. The elevation of OTR expression in the isthmic is to induce an increase uterine contractility of the isthmic part in the proliferative phase. As reported, the velocity and frequency of uterine contractions were maximized at the

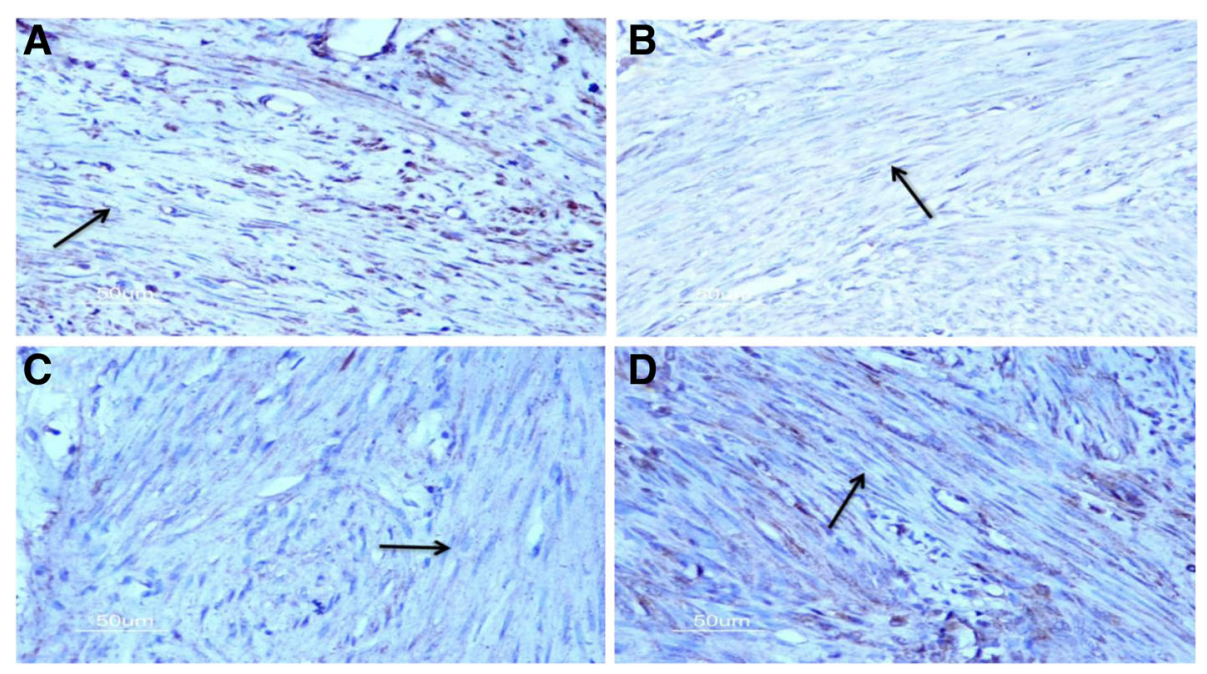

Fig. 1 Representative staining of mild cytoplasmic OTR expression in myometrial cells of JZ in the control group (arrow). a Isthmus region in the proliferative phase. $\mathbf{b}$ Fundus in the proliferative phase. $\mathbf{c}$ Isthmus region in the secretory phase. $\mathbf{d}$ Fundus region in the secretory phase 


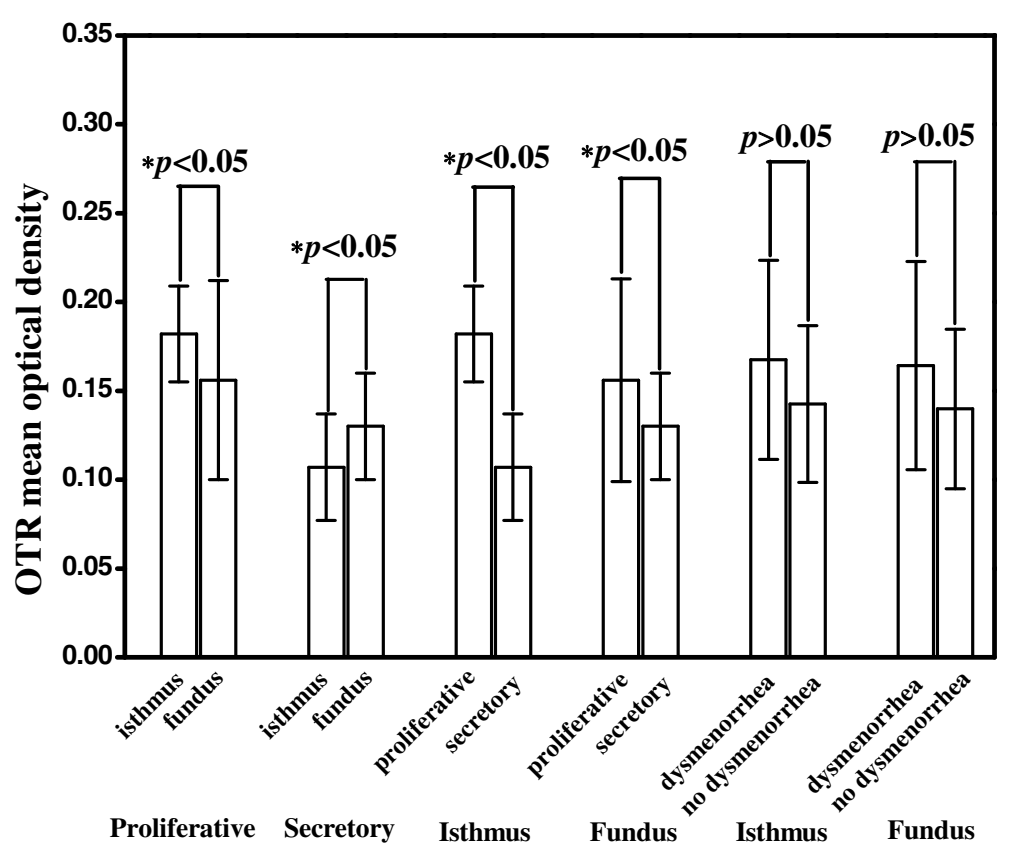

Fig. 2 Comparisons of oxytocin expression level in the isthmus and fundus of control uterus in different menstrual cycles. OTR expression in the isthmic region was significantly higher than in the fundal region in the proliferative phase $(p<0.05)$ but significantly lower in the secretory phase $(p<0.05)$. In both isthmic and fundal regions, OTR expression in the proliferative phase was significantly higher than that in the secretory phase $(p<0.05)$. OTR expression in patients with dysmenorrhea of control group was no significant difference from that of patients without in both isthmic and fundal regions of JZ ( $p>0.05)$. Data are expressed as mean \pm standard error of the mean

pre-ovulatory phase of the follicular cycle. They also surveyed that constructions of cervix to fundal pattern were dominant at this phase of the follicular cycle [25-28]. This type of uterine contractions, which aspirate sperm into the cervical part and the uterine cavity, controls the rapid sustained sperm transport and provides forces into the isthmic part of the tubes where they are available for fertilization [29]. In contrast, OTRs were significantly lower in the isthmic part in the secretory phase. The uterine contraction wave at the luteal phase consists of cervico-fundal contractions and isthmus contractions [30]. Both types of uterine peristaltic activities become less frequent by the end of the menstrual cycle. For each contraction started in the isthmical region, only one fourth reaches the fundal region in the late luteal phase. This means the contractions render the fundal region with relative peristaltic quiescence during the late luteal phase and minimizes the mechanical irritation of embryo implantation.

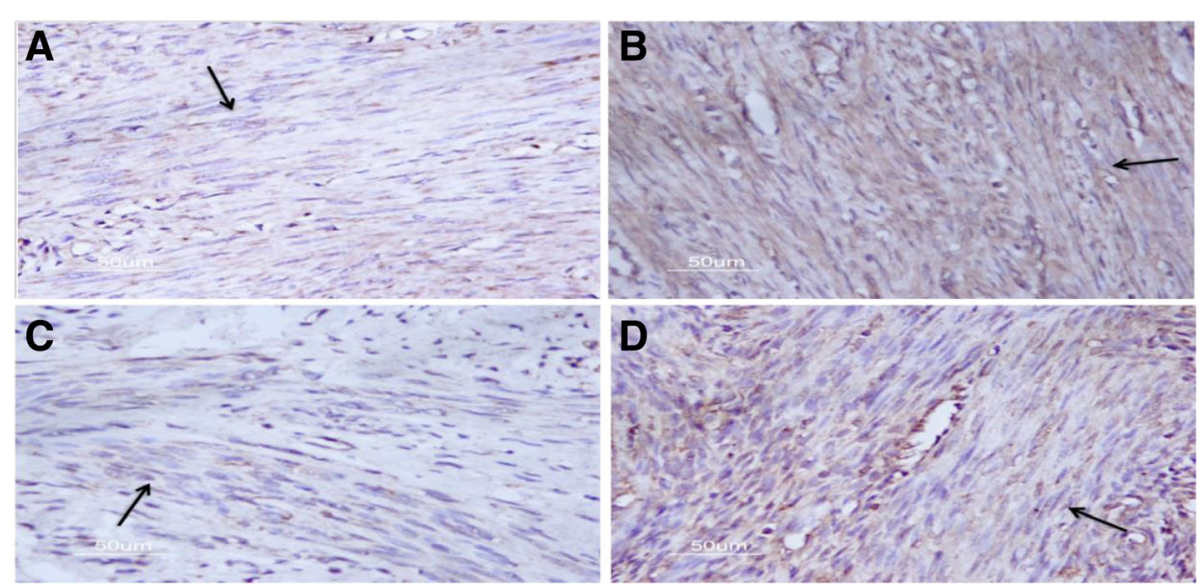

Fig. 3 Representative staining of strong cytoplasmic OTR expression in myometrial cells of JZ in the endometriosis group (arrow). a Isthmus region in the proliferative phase. $\mathbf{b}$ Fundus in the proliferative phase. $\mathbf{c}$ Isthmus region in the secretory phase. $\mathbf{d}$ Fundus region in the secretory phase 


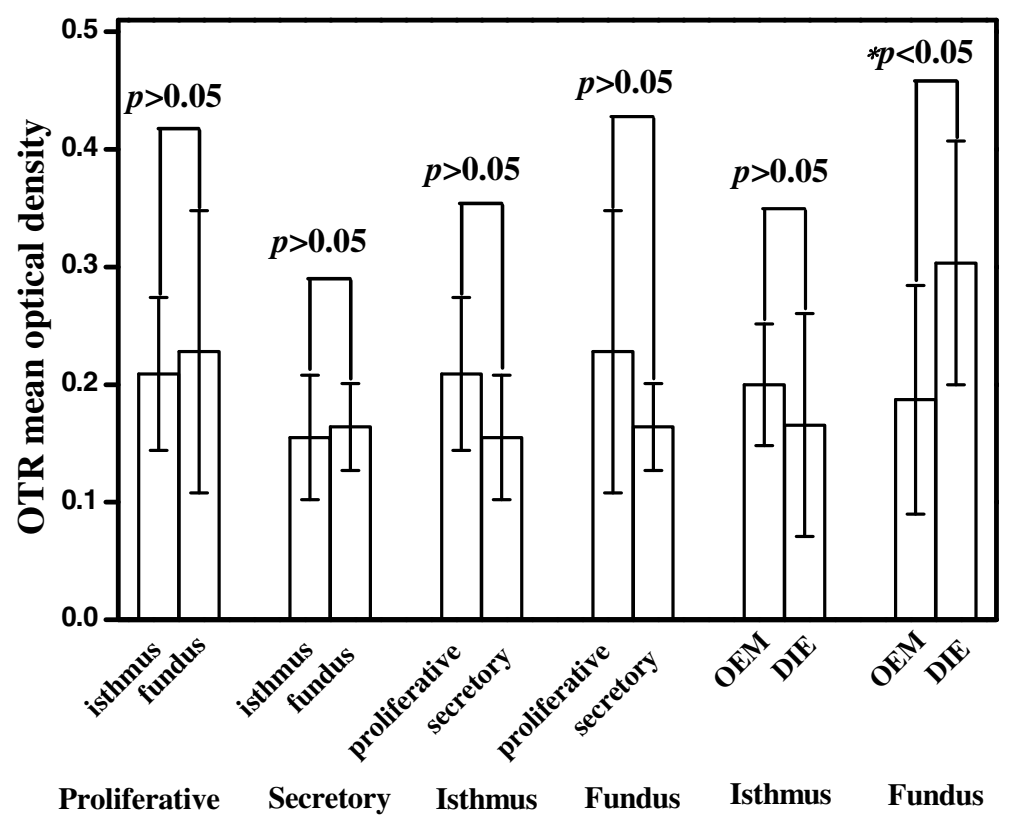

Fig. 4 Comparisons of oxytocin expression level in the isthmus and fundus of endometriosis uterus in different menstrual cycles. OTR expression was not significantly between the isthmic and fundal regions in both proliferative and secretory phases. $(p>0.05)$. In both isthmic and fundal regions, the expression of OTR in the proliferative phase was not significantly different from secretory phase $(p>0.05)$. In the fundal region of JZ, the expression of OTR in ovarian endometriosis was significantly lower than that in deep infiltrating endometriosis $(p<0.05)$. Data are expressed as mean \pm standard error of the mean

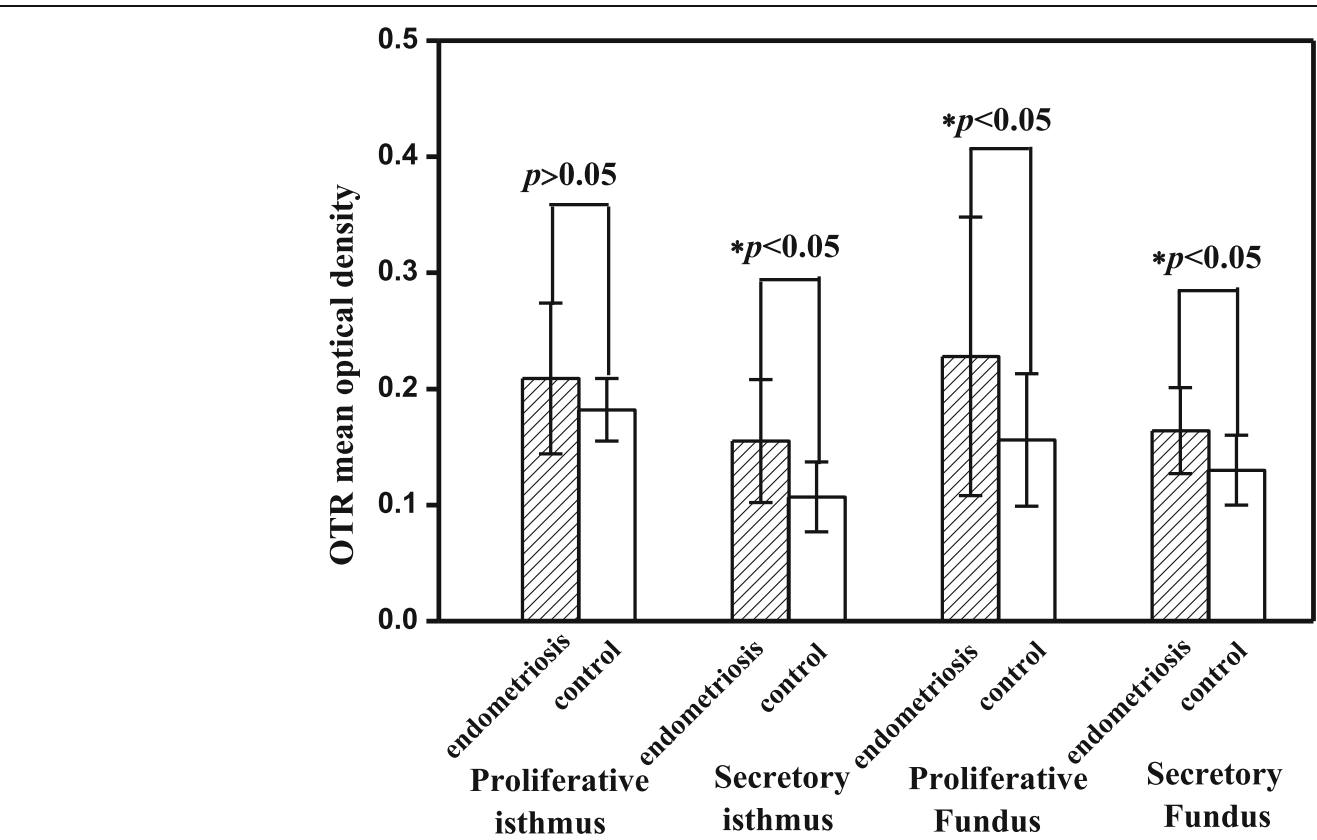

Fig. 5 Comparisons of oxytocin receptor expression level between control and endometriosis uteri in the proliferative and secretory phases. In the isthmic region, the expression of OTR in the secretory phase was significantly higher in the endometriosis uteri $(p<0.05)$. In the fundal region of endometriosis uteri, the expression of OTR was significantly higher than that in the control uteri in both the proliferative and the secretory phases $(p<0.05)$. Data are expresses as mean \pm standard error of the mean 


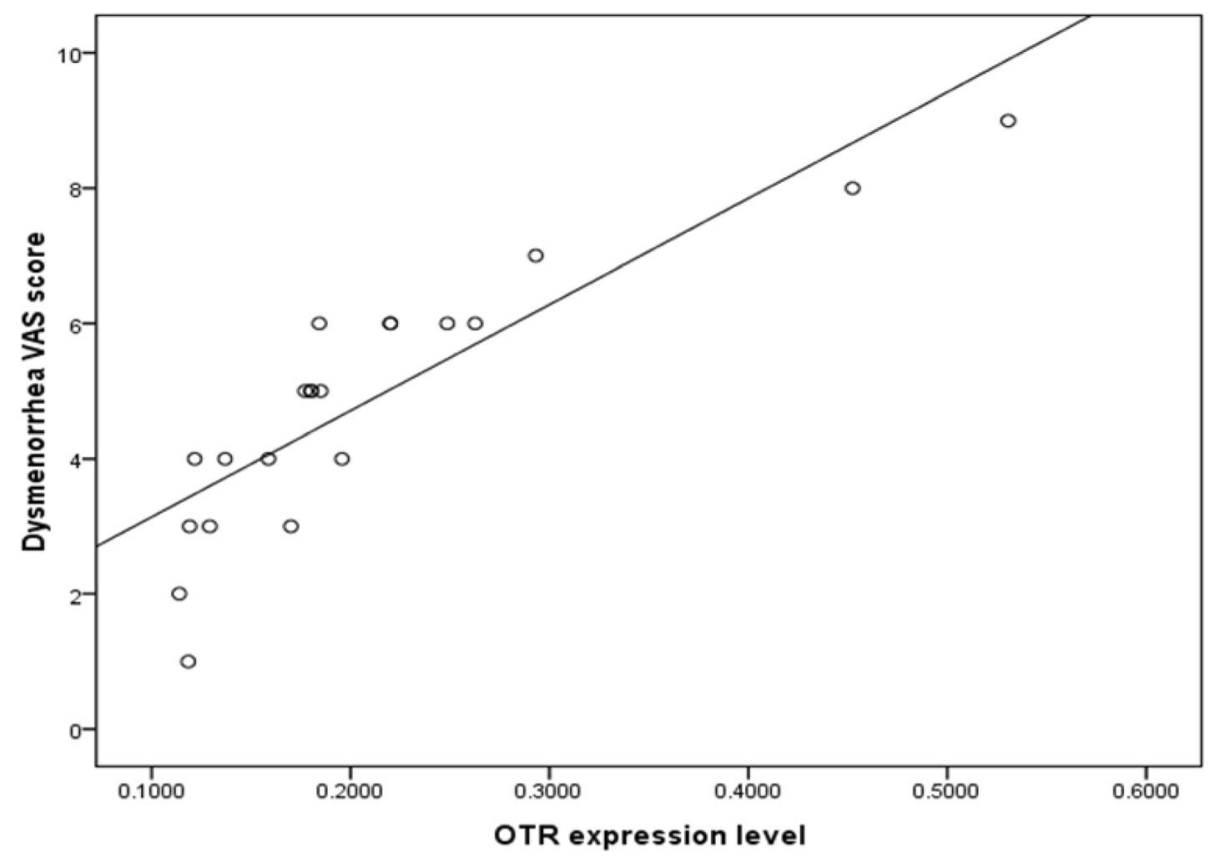

Fig. 6 The severity of dysmenorrhea measured by the VAS as function of the OTR expression levels in women with endometriosis. OTR expression level in the funds region is positively correlated with the severity of dysmenorrhea $(r=0.872, p<0.05)$

In uterine myometrial cells, OTR expressions are induced by estradiol stimulation and down-regulated by progesterone application [31-34]. OTR concentrations are higher during the proliferative phase than the secretory phase [35-37]. Consistent with these findings, our study revealed OTR expression of control uteri in the proliferative phase showed higher significance difference compared with that in the secretory phase in both isthmic region and fundal region, presumably reacting the positive and negative effects of estrogen and progesterone activity on oxytocin receptor synthesis and degradation respectively $[31,38]$. 17ß-estradiol (E2), which can be locally secreted by endometriotic cells, plays a vital role in development and progression of endometriosis [39]. The OTR distribution in endometriosis uteri is altered by excessive estrogen. OTR expression was not significantly different between the isthmic and fundal regions at either proliferative or secretory phases. This may be one reason why endometriosis had an obvious uterine hyperperistalsis and dysperistalsis, which prejudice the forces for rapid and sustained sperm transport into tube ipsilateral to the dominant follicle $[12,18,29]$.

Women with endometriosis display a marked increase in uterine contraction compared with women free of disease $[15,16,40]$. The frequency of peristaltic activity is doubled at the early and mid-menstrual phase of the cycle compared with normal women [15]. The frequency of peristaltic activity is similar to that obtained in normal women with intravenous injection of oxytocin [41].
During menstruation, the frequency, amplitude and incidence of retrograde uterine contractions in women with endometriosis were much higher than in women without endometriosis [42]. Our previously study revealed women with endometriosis displayed higher frequency uterine contract activity. We also found that dysperistalsis uterine contractions referred to some of the contractions originating in the middle portion of the uterus and spreading simultaneously to the fundus and the cervix. Other contractions that started simultaneously at different sites vanished before they had reached the fundal part of the uterus [16]. Hysterosalpingoscintigraphy revealed that in the early and mid-follicular phases, women with endometriosis displayed hyperperistalsis that resulted in a dramatic increase transportation of inert particles from the vagina, through the uterus into the oviduct and also into the peritoneal cavity [15]. Hyperperistalsis results in desquamation of viable fragments of basal endometrium and enhanced trans-tubal dissemination of these fragments. These fragments might implant some certain sites of the peritoneal cavity [18]. These viable endometrial cells ultimately develop into endometriotic implants. Therefore, the alterations of uterine peristaltic activity play a causal role in the pathogenesis of endometriosis. As reported, volumes of endometriotic implants in rats were significantly reduced by treatment with an OTR antagonist. It indicated that an OTR antagonist may be an important effective drug to decrease dissemination and thereby to combat 
endometriosis [43]. Blocking OTRs for endometriosis treatment may indirectly inhibit the synthesis aromatase enzyme and the controlled hyper-estrogenic state of the implants.

Dysmenorrhea is related to an elevated basal intrauterine pressure tone and alters the frequency, amplitude and duration of uterine contraction [44]. Since uterine contractions of the JZ in non-pregnant uterus are oxytocin dependent, OTR may be involved in dysmenorrhea. Combining with oxytocin, excessive and irregular oxytocin receptor causes higher intrauterine pressure which is related to dysmenorrhea. Our previous study displayed that women with endometriosis showed higher serum oxytocin level [16]. As reported, the uterus contractile amplitude and OTR expression level in myometrial smooth muscle cells were both significantly higher in adenomyosis cases than in controls, and related positively to adenomyosis-associated dysmenorrhea which is connected with increased uterine contractility. Andrographolide which inhibits OTR expression can normalize uterine contractility and pain alleviation [13]. DIE is recognized as the most severe clinical form of endometriosis and it is associated with severe pain symptom [45]. This maybe can explain the OTR expression in fundal region of JZ in DIE endometriosis patients was higher than that of OEM patients. OTR expression change in the myometrial architecture of uteri having adenomyosis support the hypothesis that dysperistalsis plays an essential role in the development of endometriosis and dysmenorrhea [23]. Besides the cause of uterine hyperactivity, OTR expression up-regulates COX-2 and $\mathrm{PGF}_{2 \alpha}$ which is known as a pain mediator [46]. PGF2 $\alpha$ can further increase the level of Oxytocin and $\mathrm{PGE}_{2}$ [47-50]. PGF2 $\alpha$ Combed with $\mathrm{PGE}_{2}$, can cause $\mathrm{COX}-2$ overproduction [51], which in turn increases $\mathrm{PGE}_{2}$ synthetize, and thereby causes dysmenorrhea in endometriosis. Similarly, we provide that endometriosis-associated dysmenorrhea correlates positively with OTR expression level in the JZ (Fig. 6). The main limitation of our study was small size. We believe that this result needs future larger, adequately powered investigation.

In normal uterus, uterine contraction frequency and amplitude increased from mid-cycle to maximum values in the late luteal phase. Retrograde uterine activity is most frequent at mid-cycle, which ensures the sperm transport to the distal end of the tubes [28]. In the isthmic region of endometriosis uteri, the expression of OTR showed no significant difference in both the proliferative and secretory phase. At mid-cycle, peristaltic activities in women with endometriosis are replaced by more convulsive uterine activities [15]. This change has a profound effect on the directed sperm transport. Passive sperm transport in the pre-ovulatory is impeded dramatically by uterine dysperistlasis, which induce a reduced aspiration of sperm into the uterine cavity and a seriously impaired directed transport into the tube ipsilateral to the dominant follicle [15]. We assume that the inefficient sperm transport induced by decreased peristalsis may be involved in infertility associated with endometriosis.

This study reveals the expression of OTR in the fundal region in endometriosis uteri was significantly higher compared with normal uteri in both the proliferative and secretory phases. We also displayed that uterine contract activities were positively correlated with serum of oxytocin levels and patients with endometriosis had higher frequency uterine contractions than in the tubal factor group in our former experiments [16, 52]. Thus, we speculated the OT/OTR system in endometriosis may result in hyperperistalsis and poor endometrial receptivity. Uterine peristalsis provides the forces for embryo migration, but adversely affects the likelihood of pregnancy if the peristaltic frequency is too high [53]. It is estimated that uterine contraction at the time of embryo transfer, especially fund-cervical contractile activity, could expel embryos from the uterus [54]. Patients with uterine peristalsis of $>3.0$ waves $/ \mathrm{min}$ before embryo transfer had a lower chance of pregnancy compared with those with lower frequencies [55]. In our previous study, uterine contractions were harmful to embryo implantation and women with more uterine contract activities are more likely to be repeated implantation failures [51]. Atosiban, can compete with OT of OTR in uterine smooth muscle cells, decidual cells, and fetal membranes and inhibits OT-induced PGF2a and uterine activities [56]. Some perspective cohort studies show that atosiban may benefit patients who suffer from repeated or once implantation failure undergoing IVF/embryo transfer with cryopreserved embryos [57-59]. Our former study has indicated application of atosiban improved the clinical pregnancy and implantation rates in patients with emdometriosis-associated infertility [16]. Atosiban can relax uterine arteries and improve uterine endometrial receptivity in pregnant rats $[60,61]$. One potential mechanism about the beneficial effects of atosiban on implantation and pregnancy is its inhibitory effects on uterine contractions [57].

\section{Conclusions}

The OTR expression in the uterine junctional zone of women with endometriosis appears to have changed significantly and irregularly. The abnormal expression pattern of oxytocin receptor in the JZ in women with endometriosis may result in abnormal uterine contractile activity, reduced fertility and dysmenorrhea associated with endometriosis. 


\section{Abbreviations}

CINIII: Cervical intraepithelial neoplasia; JZ: Junctional zone; OT: Oxytocin; OTR: Oxytocin receptor; VIS: Visual analogue scale

\section{Acknowledgements}

The authors wish to thank the help from Dr. Jianye Wang and all patients enrolled in Department of Gynecology and Obstetrics, the Affiliated Hospital of Anhui Medical University.

\section{Funding}

The research was supported by Planning Project Supported by 'Twelve-Five' National Science and Technology (2012BAl3201).

\section{Availability of data and materials}

The data analyzed during the research is available upon request from corresponding author.

\section{Authors' contributions}

$\mathrm{MH}$ and $\mathrm{XL}$ contributed equally to this work. They performed, analyzed and interpreted the histological examinations, performed statistical analyses and contributed to writing the manuscript; PG interpreted the histological examinations and assisted with statistical analyses; ZY analyzed the histological examinations and contributed to conceptualization of the study; YX participated in the recruitment of patients and edited the manuscript for key content; ZW analyzed and interpreted the data, assisted with statistical analyses, edited and revised the manuscript. All authors read and approved the final manuscript

\section{Competing interests}

The authors declare that they have no competing interests.

\section{Consent for publication}

Subjects gave their informed consent for research participation.

\section{Ethics approval and consent to participate}

The study was approved by the Clinical Research Ethics Committee of the First Affiliated Hospital of Medical University of Anhui (PJ20160409).

Received: 31 August 2016 Accepted: 12 December 2016 Published online: 03 January 2017

\section{References}

1. Vignali M, Infantino M, Matrone R, Chiodo I, Somigliana E, Busacca M, Vigano P. Endometriosis: novel etiopathogenetic concepts and clinical perspectives. Fertil Steril. 2002;78(4):665-78.

2. Giudice LC, Kao LC. Endometriosis. Lancet. 2004;364(9447):1789-99.

3. Naftalin J, Jurkovic D. The endometrial-myometrial junction: a fresh look at a busy crossing. Ultrasound Obstet Gynecol. 2009;34(1):1-11.

4. Brosens JJ, de Souza NM, Barker FG. Uterine junctional zone: function and disease. Lancet. 1995;346(8974):558-60.

5. Kunz G, Noe M, Herbertz M, Leyendecker G. Uterine peristalsis during the follicular phase of the menstrual cycle: effects of oestrogen, antioestrogen and oxytocin. Hum Reprod Update. 1998;4(5):647-54

6. De ZD, Bulletti C, Farichin R, Epinery M, Broschi PA. Contractility of the non-pregnant uterus: the follicular phase. Ann N Y Acad Sci. 2001:943:172-84

7. Vries KD, Lyons EA, Ballard G, Levi CS, Lindsay DJ. Contractions of the inner third of the myometrium. Am J Obstet Gynecol. 1990;162(3):679-82.

8. Kunz G, Leyendecker G. Uterine peristaltic activity during the menstrual cycle: characterization, regulation, function and dysfunction. Reprod Biomed Online. 2002;4(Suppl3):5-9.

9. Lesny P, Killick SR. The junctional zone of the uterus and its contractions. BJOG. 2004:111(11):1182-9.

10. Exacoustos C, Luciano D, Corbett B, Felice GD, Feliciantonio MD Luciano $\mathrm{A}$, et al. The uterine junctional zone: a 3-dimensional ultrasound study of patients with endometriosis. Am J Obstet Gynecol. 2013;209(3):248.e1-7.

11. Tosti C, Zupi E, Exacoustos C. Could the uterine junctional zone be used to identify early-stage endometriosis in women? Womens Health (Lond Engl). 2014;10(3):225-7.
12. Leyendecker G, Kunz G, Wildt L, Beil D, Deininger $H$. Uterine hyperperistalsis and dysperistalsis as dysfunctions of the mechanism of rapid sperm transport in patients with endometrisos and infertility. Hum Reprod. 1996;11(7):1542-51.

13. Guo SW, Mao XY, Ma QL, Liu XS. Dysmenorrhea and its severity are associated with increased uterine contractility and overexpression of oxytocin receptor (OTR) in women with symptomatic adenomyosis. Fertil Steril. 2013;99:231-40.

14. Sylvia M, Julia B, Christoph L, Salomon DS, Starzinski-Powitz A, Ebert AD. Oxytocin receptor expression in smooth muscle cells of peritoneal endometriotic lesions and ovarian endometriotic cysts. Fertil Steril. 2005;83 Suppl 1:1220-31.

15. Richter ON, Bartz C, Dowaji J, Kupka M, Reinsberg J, Ulrich U, et al. Contractile reactivity of human myometrium in isolated non-pregnant uteri. Hum Reprod. 2006:21(1):36-45.

16. He Y, Wu H, He XJ, Xing Q, Zhou P, Cao YX, et al. Administration of atosiban in patients with endometriosis undergoing frozen-thawed embryo transfer: a prospective, randomized study. Fertil Steril. 2016;106(2):416-22.

17. Aguilar HN, Mitchell BF. Physiological pathways and molecular mechanism regulating uterine contractility. Hum Reprod Update. 2010;16:725-44.

18. Leyendecker G, Kunz G, Herbertz M, Beil D, Huppert P, Mall G, et al. Uterine peristaltic activity and the development of endometriosis. Ann N Y Acad Sci. 2004;1034:338-55.

19. Sofic A, Selimovic AH, Carovac A, Jahic E, Smailbegovic V, Kupusovic J. The significance of MRI Evaluation of the Uterine Junctional Zone in the Early Diagnosis of Adenomyosis. Acta Inform Med. 2016;24(2):103-6.

20. Zhang Y, Yu P, Sun FJ, Li TC, Cheng JM, Duan H. Expression of oxytocin receptors in the uterine junctional zone in women with adenomyosis. Acta Obstet Gynecol Scand. 2015;94(4):412-8.

21. Novellas S, Chassang M, Delotte J, Toullalan O, Chevallier A, Bouazin J, Chevallier P. MRI characteristics of the uterine junctional zone: from normal to the diagnosis of adenomyosis. AJR Am J Roentgenol. 2011:196(5):1206-13.

22. Tsigkou A, Reis FM, Ciarmela P, Lee MH, Jing BJ, Tosti C, et al. Expression levels of myostatin and matrix metalloproteinase 14 mRNAs in uterine leiomyoma are correlated with dysmenorrhea. Reprod Sci. 2015;22(12):1597-602.

23. Mechsner S, Grum B, Gericke C, Loddenkemper C, Dudenhausen JW, Ebert AD. Possible roles of oxytocin receptor and vasopressin-1 a receptor in the pathomechanism of dysperistalsis and dysmenorrhea in patients with adenomyosis uteri. Fertil Steril. 2010;94(7):2541-6.

24. Kido A, Togashi K, Nishino M, Miyake K, Koyama T, Fujimoto R, et al. Cine MR imaging of uterine peristalsis in patients with endometriosis. Eur Radiol. 2007;17(7):1813-9.

25. Lyons EA, Taylor PJ, Zengh XH, Ballard G, Levi CS, Kredentser JV. Characterisation of subemdometrial contractions throughout the men-strual cycle in normal fertile women. Fertil Steril. 1991:55(4):771-4

26. Ijland MM, Evers JLH, Dunselman GAJ, Van-Katwijk C, Lo CR, Hoogland HJ. Endometrial wavelike movements during the menstrual cycle. Fertil Steril. 1996;65(4):746-9.

27. Ijland MM, Evers JL, Hoogland HJ. Velocity of endometrial wavelike activity in spontaneous cycle. Fertil Steril. 1997;68(1):72-5.

28. Bulletti C, de Ziegler D, Polli V, Diotallevi L, Del Ferro E, Flamigni C. Uterine contractility during the menstrual cycle. Hum Reprod. 2000;15(Supple 1):81-9.

29. Kunz G, Beil D, Deininger $H$, Wildt $L$, Leyendecker $G$. The dynamics of rapid sperm transport through the female genital tract: evidence from vaginal sonography of uterine peristalsis and hysterosalpingoscintigraphy. Hum Reprod. 1996;11(3):627-32.

30. Kunz G, Leyendecker $G$. Uterine peristaltic activity during the menstrual cycle: characterization, regulation, function and dysfunction. Reprod BioMed Online. 2001;4(supple 3):5-9.

31. Richter ON, Kubler K, Schmolling J, Kupka M, Reinsberg J, Ulrich U, et al. Oxytocin receptor gene expression of estrogen-stimulated human myometrium in extracorporeally perfused non-pregnant uteri. Mol Hum Reprod. 2004;10(5):339-46.

32. Wathes DC, Mann GE, Payne JH, Riley PR, Stevenson KR, Lamming GE. Regulation of oxytocin, oestradiol and progesterone receptor concentrations in different uterine regions by oestradiol, progesterone and oxytocin in ovariectomized ewes. J Endocrinol. 1996;151(3):375-93.

33. Robinson RS, Mann GE, Lamming GE, Wathes DC. Expression of oxytocin, oestrogen and progesterone receptors in uterine biopsy samples throughout the oestrous cycle and early pregnancy in cows. Reproduction. 2001;122(6):965-79. 
34. Ndiaye K, Poole DH, Pate JL. Expression and regulation of functional oxytocin receptors in bovine T lymphocytes. Biol Reprod. 2008;78(4):786-93.

35. Fuchs AR, Fuchs F, Soloff MS. Oxytocin receptors in nonpregnant human uterus. J Clin Endocrinol Metab. 1985;60(1):37-41.

36. Noe M, Kunz G, Herbertz M, Mall G, Leyendecker G. The cyclic pattern of the immunohistochemical expression of oestrogen and progesterone receptors in human myometrial and endometrial layers: characterization of the endometrial-subendometrial unit. Hum Reprod. 1999;14:190-7.

37. Lessey BA, Killiam AP, Metzger DA, Haney AF, Greene GL, McCarty KSJ. Immunohistochemical analysis of human uterine estrogen and progesterone receptors throughout the menstrual cycle. J Clin Endocrinol Metab. 1988;67(2):334-9.

38. Richter ON, Tschubel K, Schmolling J, Kupka M, Ulrich U, Wardelmann E. Immunohistochemical reactivity of myometrial oxytocin receptor inextracorporeally perfused nonpregnant human uteri. Arch Gynecol Obstet. 2003;269(1):16-24.

39. Delvoux B, Groothuis P, D'Hooghe T, Kyama C, Dunselman G, Romano A Increased production of 17beta-estradiol in endometriosis lesions is the result of impaired metabolism. J Clin Endocrinol Metab. 2009;94(3):876-83.

40. Salamanca A, Beltran E. Subendometrial contractility in menstrual phase visualized by transvaginal sonography in patients with endometriosis. Fertil Steril. 1995;64(1):193-5.

41. Leyendecker G, Kunz G, Noe M, Herbertz M, Mall G. Endometriosis: a dysfunction and disease of the archimetra. Hum Reprod Update. 1998;4(5):752-62.

42. Bulletti C, De Ziegler D, Polli V, Del Ferro E, Palini S, Flamigni C. Characteristics of uterine contractility during menses in women with mild to moderate endometriosis. Fertil Steril. 2002;77(6):1156-61.

43. Simsek Y, Celik O, Karaer A, Gul M, Yilmaz E, Koc O, et al. Therapeutic efficiency of Atosiban, an oxytocin receptor blocking agent in the treatment of experimental endometriosis. Arch Gynecol Obstet. 2012;286(3):777-83.

44. Woodbury RA, Torpin R, Child GP, Watson H, Jarboe M. Myometrial physiology and its relation to pelvic pain. J Am Med Assoc. 1947;134(13):1081-5.

45. Yi $D$, Jinghua $L$, Jinghe $L$, Xiaoyan $L$. Anatomical distribution of pelvic deep infiltrating endometriosis and its relationship with pain symptoms. Chin Med J (Engl). 2012;125(2):209-13.

46. Kim S, Choi Y, Spencer TE, Bazer FW. Effect of the estrous cycle, pregnancy and interferon tau on expression of cyclooxygenase two (COX-2) in ovine endometrium. Reprod Biol Endocrinol. 2003;1:58-67.

47. Stormshak F. Biochemical and endocrine aspects of oxytocin production by the mammalian corpus luteum. Reprod Biol Endocrinol. 2003;1:92-8.

48. Wilson T, Liggins GC, Whittaker DJ. Oxytocin stimulates the release of arachidonic acid and prostaglandin F2 alpha from human decidual cells. Prostaglandins. 1988;35(5):771-80

49. Burns PD, Mendes JJ, Yemm RS, Clay CM, Nelson SE, Hayes SH, et al. Cellular mechanisms by which oxytocin mediates ovine endometrial prostaglandin F2alpha synthesis: role of $\mathrm{G}(\mathrm{i})$ proteins and mitogen-activated protein kinases. Biol Reprod. 2001;65(4):1150-5.

50. Siemieniuch MJ, Mlynarczuk JJ, Skarzynski DJ, Okuda K. Possible involvement of oxytocin and its receptor in the local regulation of prostaglandin secretion in the cat endometrium. Anim Reprod Sci. 2011;123(1-2):89-97.

51. Sales KJ, Jabbour HN. Cyclooxygenase enzymes and prostaglandins in pathology of the endometrium. Reproduction. 2003;126(5):559-67.

52. He Y, Wu H, He XJ, Xing Q, Zhou P, Cao YX, et al. Application of atosiban in frozen-thawed cycle patients with different times of embryo transfer. Gynecol Endocrinol. 2016;5:1-5.

53. Zhu L, Xiao L, Che HS, Li YP, Liao JT. Uterine peristalsis exerts control over fluid migration after mock embryo transfer. Hum Reprod. 2014;29(2):279-85.

54. Lesny P, Killick SR, Tetlow RL, Manton DJ, Robinson J, Maguiness SD. Ultrasound evaluation of the uterine zonal anatomy during in-vitro fertilization and embryo transfer. Hum Reprod. 1999;14(6):1593-8.

55. Zhu L, Che HS, Li YP. Uterine peristalsis before embryo transfer affects the chance of clinical pregnancy in fresh and frozen-thawed embryo transfer cycles. Hum Reprod. 2014;29(6):1238-43.

56. Husslein P, Quartarolo JP. Review of clinical experience with atosiban and the Tractocile Efficacy Assessment Survey in Europe (TREASURE) study protocol. Int J Clin Pract. 2003;57(2):121-7.

57. Lan VT, Khang VN, Nhu GH, Tuong HM. Atosiban improves implantation and pregnancy rates in patients with repeated implantation failure. Reprod BioMed Online. 2012;25:254-60.
58. Song XR, Zhao XH, Bai XH, Lü YH, Zhang HJ, Wang YX, et al. Application of oxytocin receptor antagonist in thaw embryo transfer. Zhonghua Fu Chan Ke Za Zhi. 2013;48(9):667-70.

59. Decleer W, Osmanagaoglu K, Devroey $P$. The role of oxytocin antagonists in repeated implantation -failure. Facts Views Vis Obgyn. 2012;4(4):227-9.

60. Pierzynski P, Reinheimer TM, Kuczynski W. Oxytocin antagonists may improve infertility treatment. Fertil Steril. 2007:88(1):213.e19-22.

61. Vedernikov Y, Betancourt A, Shi SQ, Shi LL, Reinheimer T, Garfield RE. Oxytocin antagonistic effect of barusiban and atosiban in isolated uterine artery from late pregnant rats. J Soc Gynecol Invest. 2006;13:192a.

\section{Submit your next manuscript to BioMed Central and we will help you at every step:}

- We accept pre-submission inquiries

- Our selector tool helps you to find the most relevant journal

- We provide round the clock customer support

- Convenient online submission

- Thorough peer review

- Inclusion in PubMed and all major indexing services

- Maximum visibility for your research

Submit your manuscript at www.biomedcentral.com/submit
Biomed Central 